\title{
Use of Topical Tacrolimus and Topical Pimecrolimus in Four European Countries: A Multicentre Database Cohort Study
}

\author{
Josephina G. Kuiper $^{1}$ (1) $\cdot$ Myrthe P. P. van Herk-Sukel $^{1,8} \cdot$ Jordi Castellsague $^{2}$ • \\ Anton Pottegård $^{3}$ - Ingegärd Anveden Berglind ${ }^{4} \cdot$ Daniel Dedman $^{5} \cdot$ Lia Gutierrez $^{2}$. \\ Brian Calingaert $^{6}$ - Jesper Hallas ${ }^{3}$ - Anders Sundström ${ }^{4} \cdot$ Arlene M. Gallagher $^{5}$. \\ James A. Kaye ${ }^{6} \cdot$ Carolina Pardo $^{7} \cdot$ Kenneth J. Rothman $^{6} \cdot$ Susana Perez-Gutthann $^{2}$
}

Published online: 7 May 2018

(C) The Author(s) 2018

\begin{abstract}
Background Despite the concerns about a potential increased risk of skin cancer and lymphoma with the use of topical tacrolimus and pimecrolimus, no population-based studies have given an overview of the use of these drugs in Europe.

Objective To assess the use of topical tacrolimus and pimecrolimus in children and adults in Europe.

Methods Multicentre database cohort study comprising data from the Netherlands, Denmark, Sweden and the UK. We analysed users of topical tacrolimus and pimecrolimus starting from the date of first availability (between 2002 and 2003) or start establishment of the prescription
\end{abstract}

Josephina G. Kuiper

josine.kuiper@pharmo.nl

1 PHARMO Institute for Drug Outcomes Research, Van Deventerlaan 30-40, 3528 AE Utrecht, The Netherlands

2 Epidemiology, RTI Health Solutions, Av. Diagonal, 605, 9-1, 08028 Barcelona, Spain

3 Department of Public Health, University of Southern Denmark, J.B. Winsløws Vej 9B, 5000 Odense, Denmark

4 Unit of Clinical Epidemiology, Department of Medicine, Centre for Pharmacoepidemiology, Karolinska Institutet, Solnavägen 1, 17177 Stockholm, Sweden

5 Clinical Practice Research Datalink, Medicines and Healthcare products Regulatory Agency, 151 Buckingham Palace Road, Victoria, London SW1W 9SZ, UK

6 Epidemiology, RTI Health Solutions, Research Triangle Park, 3040 Cornwallis Road, Research Triangle Park, NC 27709-2194, USA

7 Pharmacovigilance Department, Astellas Pharma Europe, Sylviusweg 62, 2333 BE Leiden, The Netherlands

8 University Medical Center Utrecht, Heidelberglaan 100, 3584 CX Utrecht, The Netherlands database in Sweden (2006) through 2011. Use was assessed separately for children ( $\leq 18$ years) and adults.

Results 32,052 children and 104,902 adults were treated with topical tacrolimus, and 32,125 children and 58,280 adults were treated with topical pimecrolimus. The number of users increased rapidly after first availability, especially for topical tacrolimus. Topical tacrolimus was more frequently used in all countries except Denmark. For both drugs, there was a decrease in users after 2004 in the Netherlands and Denmark and after 2005 in the UK, especially among children. This decrease was largest in Denmark. The decrease in the number of users was temporary for topical tacrolimus, while use remained relatively low for topical pimecrolimus.

Conclusions The number of topical tacrolimus and pimecrolimus users increased rapidly after regulatory approval. A transient reduction in topical tacrolimus use and a persistent reduction in topical pimecrolimus use was seen after 2004 in the Netherlands and Denmark and after 2005 in the UK.

\section{Key Points}

This multidatabase cohort study assessed the use of topical tacrolimus and topical pimecrolimus in children and adults in Europe.

The number of users of topical tacrolimus and topical pimecrolimus increased rapidly after regulatory approval.

A transient reduction in topical tacrolimus use and a persistent reduction in topical pimecrolimus use was seen after 2004 in the Netherlands and Denmark and after 2005 in the UK. 


\section{Introduction}

Atopic dermatitis (AD) is a chronic inflammatory skin disease with a wide range of clinical presentations and is one of the most common skin disorders in children [2, 3]. For many years, the most common treatment for AD was topical corticosteroids. In 2002, new topical treatment options in the form of tacrolimus ointment and pimecrolimus cream were approved for the treatment of $\mathrm{AD}$. Topical tacrolimus and topical pimecrolimus are the only topical calcineurin inhibitors (TCIs) in Europe. In 2002, topical tacrolimus was approved for short or intermittent long-term treatment of moderate to severe AD in Europe. Two concentrations of topical tacrolimus are available; $0.1 \%$ for use in patients over 16 years of age, and $0.03 \%$ for use in children over 2 years of age. The indication for topical tacrolimus was extended in 2009 to maintenance treatment of AD. Topical pimecrolimus in a concentration of $1 \%$ was approved in 2002 for the treatment of mild-tomoderate $\mathrm{AD}$ in patients over 2 years of age. Both drugs are approved for second-line treatment only, for patients in whom other treatments have been ineffective or are contraindicated.

At the time of approval of both products, the long-term safety in humans was not fully established, though animal studies indicated a potential risk of skin cancer of both products [4, 5]. In March 2005, the US Food and Administration (FDA) issued a public health advisory followed by a label change in January 2006, including a boxed warning $[6,7]$. Similarly, the European Medicines Agency's Committee for Medicinal Products for Human Use (CHMP) recommended a change in the product information and a Direct Healthcare Professional Communication (DHPC) letter was sent by the marketing authorization holders of topical tacrolimus and topical pimecrolimus to healthcare professionals with important risk minimization measures [8].

To date, no population-based studies have given an overview of the use of topical tacrolimus and topical pimecrolimus for the treatment of AD in Europe. Therefore, the purpose of this population-based study is to give an overview of the use of topical tacrolimus and topical pimecrolimus across population-based health databases in four European countries between 2002 and 2011.

\section{Methods}

\subsection{Study Design and Setting}

In this multicentre database cohort study, data were retrieved from population-based health databases in four
European countries: the PHARMO Database Network (PHARMO) in the Netherlands, the Danish National Prescription Registry, the Swedish Prescribed Drug Registry, and the Clinical Practice Research Datalink (CPRD) in the UK.

The PHARMO Database Network is a population-based, patient-centric data tracking system that includes detailed information on prescribed healthcare products dispensed by the outpatient pharmacies $[9,10]$. The PHARMO Database Network covers a catchment area representing more than 4 million residents. In Denmark and Sweden, each national healthcare system provides universal coverage to all residents. The Danish National Prescription Registry started in 1995 and contains data on prescribed and dispensed medicine for all 5.7 million residents in Denmark [11]. The Swedish Prescribed Drug Registry started in July 2005 and contains data on prescribed and dispensed medicine for all 9.2 million residents in Sweden [12]. The CPRD contains data collated by General Practitioners (GPs) for over 5 million active patients representing over $8 \%$ of the general population and includes detailed information on prescriptions issued in primary care [13]. Drug dispensings and prescriptions are coded according to the WHO Anatomical Therapeutic Chemical (ATC) Classification System in PHARMO (Netherlands), Denmark and Sweden, and according to Gemscript codes in CPRD (UK).

Hereafter, issued prescriptions recorded in CPRD are referred to as dispensings.

\subsection{Participants}

The study population in each country comprised children ( $\leq 18$ years) and adults ( $>18$ years) with a dispensing of topical tacrolimus or topical pimecrolimus between 2002 and 2011. The start of the study period differed across countries, depending on the launch date of topical tacrolimus and topical pimecrolimus in each country, and in Sweden on the establishment of the prescription database in 2005. Topical tacrolimus was available from 2002 in all countries, and topical pimecrolimus from 2002 in Denmark and from 2003 in the other countries.

\subsection{Treatment Characteristics}

In the study period, the mean total number of dispensings per patient of topical tacrolimus and topical pimecrolimus was calculated. The number of users of topical tacrolimus and topical pimecrolimus by year was also determined. For each country, the proportion of total topical tacrolimus and topical pimecrolimus users was tabulated by year. The proportion of users in each year was calculated by dividing the number of topical tacrolimus users or topical pimecrolimus users in a specific year by the total number of 
topical tacrolimus users or topical pimecrolimus users throughout the study period. The strength $(0.1$ or $0.03 \%)$ of the first topical tacrolimus dispensing was determined. The first switch between topical tacrolimus and topical pimecrolimus (or vice versa) that occurred between the first dispensing in the study period and the end of that patient's follow-up was reported.

\subsection{Statistical Analyses}

The data extraction and analysis for each database were based on a common protocol. Treatment characteristics were reported as percentages for categorical variables, and mean with standard deviation (SD) (if available) for continuous variables. All analyses were conducted within two age cohorts $(\leq 18$ years and $>18$ years) and within each data source.

\section{Results}

In total, there were 32,052 children and 104,902 adults treated with topical tacrolimus, and 32,125 children and 58,280 adults treated with topical pimecrolimus. In Denmark the most commonly used TCI for both children and adults was topical pimecrolimus, whereas topical tacrolimus was the predominant TCI choice for both age groups in the other countries. Of the study population, the most users of topical pimecrolimus were from Denmark (74\% of all children and $69 \%$ of all adults) (Table 1). Denmark and Sweden contributed together $71 \%$ of all children and $70 \%$ of all adult users of topical tacrolimus. The mean number of topical tacrolimus dispensings per child varied between 2.0 (Sweden) and 4.6 (UK). For adults, this ranged from 2.2 (Denmark and Sweden) to 3.6 (UK). The mean number of topical pimecrolimus dispensings ranged from 2.0 (Netherlands) to 2.4 (UK) among children and from 2.0 (Sweden) to 2.9 (UK) among adults.

In Sweden, the prescription registry started in July 2005 and users from January 2006 and onwards were included. Information in the first 4 years after launch of topical tacrolimus and topical pimecrolimus was therefore not available on an individual level. However, based on aggregate Swedish sales data on prescription of the drugs during the entire period of marketing (data not shown), a sharp decline in sales of topical tacrolimus was observed between 2004 and 2006 and a minor decline of topical pimecrolimus between 2004 and 2005. Across the other data sources, the number of topical tacrolimus users increased steadily after launch among both children and adults (Table 2). For topical pimecrolimus, there was a peak in the number of users in the first 2 years after its first availability, especially among children (Fig. 1). For topical tacrolimus, there was a decrease in users seen after 2004 in the Netherlands and Denmark, and after 2005 in the UK, especially among children. In the Netherlands, the year 2004 contributed $16 \%$ of the total number of children using topical tacrolimus and declined to $13 \%$ in the year 2005. In Denmark, the year 2004 contributed 14\% of the total number of children using topical tacrolimus in Denmark and also declined to $13 \%$ in the year 2005. In the UK, the year 2005 contributed $22 \%$ of the total number of children using topical tacrolimus in the UK and declined to $18 \%$ in the year 2006. For topical pimecrolimus, a decline in the number of users of topical pimecrolimus was seen after 2004 for children and after 2005 for adults in the Netherlands. This was seen after 2004 in Denmark and after 2005 in the UK for both children and adults. After 2007, there was a difference seen in the number of users between topical tacrolimus and topical pimecrolimus. In 2011, the

Table 1 Topical tacrolimus and topical pimecrolimus use, stratified by country

\begin{tabular}{|c|c|c|c|c|c|c|c|c|}
\hline & \multicolumn{4}{|c|}{ Topical tacrolimus cohort } & \multicolumn{4}{|c|}{ Topical pimecrolimus cohort } \\
\hline & $\begin{array}{l}\text { Children } \\
(\leq 18 \text { years }) \\
(N=32,052) \\
n(\%)\end{array}$ & $\begin{array}{l}\text { Mean number } \\
\text { of } \\
\text { prescriptions } \\
\text { per user }\end{array}$ & $\begin{array}{l}\text { Adults } \\
(>18 \text { years }) \\
(N=104,902) \\
n(\%)\end{array}$ & $\begin{array}{l}\text { Mean number } \\
\text { of } \\
\text { prescriptions } \\
\text { per user }\end{array}$ & $\begin{array}{l}\text { Children } \\
(\leq 18 \text { years }) \\
(N=32,125) \\
n(\%)\end{array}$ & $\begin{array}{l}\text { Mean number } \\
\text { of } \\
\text { prescriptions } \\
\text { per user }\end{array}$ & $\begin{array}{l}\text { Adults } \\
(>18 \text { years }) \\
(N=58,280) \\
n(\%)\end{array}$ & $\begin{array}{l}\text { Mean number } \\
\text { of } \\
\text { prescriptions } \\
\text { per user }\end{array}$ \\
\hline $\begin{array}{l}\text { PPHARMO } \\
\text { (NL) }\end{array}$ & $5037(16)$ & 2.7 & $19,264(18)$ & 2.7 & $3452(11)$ & 2.1 & $8,072(14)$ & 2.2 \\
\hline Denmark & $12,976(40)$ & 2.5 & $35,112(33)$ & 2.2 & $23,921(74)$ & 2.3 & $40,013(69)$ & 2.3 \\
\hline Sweden $^{\mathrm{a}}$ & $10,026(31)$ & 2.0 & $39,294(37)$ & 2.2 & $1623(5)$ & 2.0 & $4766(8)$ & 2.0 \\
\hline CPRD (UK) & $4013(13)$ & 4.6 & $11,232(11)$ & 3.6 & $3129(10)$ & 2.4 & $5429(9)$ & 2.9 \\
\hline
\end{tabular}

$N L$ Netherlands, CPRD Clinical Practice Research Datalink, UK United Kingdom

${ }^{\mathrm{a}}$ In Sweden, data from July 2005 were available, but only users from 2006 were included 
Table 2 The number of users of topical tacrolimus and topical pimecrolimus by year, stratified by country

\begin{tabular}{|c|c|c|c|c|c|c|c|c|c|c|}
\hline & 2002 & 2003 & 2004 & 2005 & 2006 & 2007 & 2008 & 2009 & 2010 & 2011 \\
\hline \multicolumn{11}{|c|}{ Topical tacrolimus cohort } \\
\hline \multicolumn{11}{|c|}{ Children $(\leq 18$ years $)$} \\
\hline PHARMO (NL) & 55 & 701 & 782 & 650 & 571 & 763 & 823 & 1020 & 1018 & 1049 \\
\hline Denmark & 550 & 1270 & 1876 & 1733 & 1424 & 680 & 1877 & 2816 & 3294 & 3486 \\
\hline Sweden $^{\mathrm{a}}$ & - & - & - & - & 1423 & 1566 & 2070 & 2482 & 2959 & 3041 \\
\hline CPRD (UK) & 302 & 639 & 784 & 902 & 734 & 662 & 655 & 800 & 828 & 920 \\
\hline \multicolumn{11}{|l|}{ Adults ( $>18$ years) } \\
\hline PHARMO (NL) & 97 & 2396 & 3399 & 3155 & 2620 & 2742 & 2853 & 3531 & 3984 & 4347 \\
\hline Denmark & 1172 & 2845 & 4097 & 3819 & 3406 & 2955 & 5348 & 7813 & 9231 & 10,532 \\
\hline Sweden $^{\mathrm{a}}$ & - & - & - & - & 5054 & 6305 & 7983 & 10,181 & 12,144 & 13,396 \\
\hline CPRD (UK) & 498 & 1251 & 1640 & 1983 & 1892 & 1926 & 1946 & 2271 & 2398 & 2543 \\
\hline \multicolumn{11}{|c|}{ Topical pimecrolimus cohort } \\
\hline \multicolumn{11}{|c|}{ Children $(\leq 18$ years $)$} \\
\hline PHARMO (NL) & - & 387 & 1108 & 720 & 453 & 523 & 494 & 452 & 360 & 329 \\
\hline Denmark & 2282 & 5352 & 6015 & 4909 & 3542 & 1827 & 2866 & 2928 & 3088 & 2842 \\
\hline Sweden $^{\mathrm{a}}$ & - & - & - & - & 465 & 398 & 376 & 346 & 300 & 265 \\
\hline CPRD (UK) & - & 488 & 811 & 869 & 601 & 396 & 368 & 374 & 346 & 350 \\
\hline \multicolumn{11}{|l|}{ Adults ( $>18$ years) } \\
\hline PHARMO (NL) & - & 424 & 1272 & 1650 & 1152 & 1337 & 1204 & 1360 & 1295 & 1454 \\
\hline Denmark & 1996 & 5667 & 7346 & 6649 & 6081 & 4610 & 5797 & 7067 & 7568 & 7984 \\
\hline Sweden $^{\mathrm{a}}$ & - & - & - & 1 & 1077 & 1028 & 1012 & 1123 & 1208 & 1099 \\
\hline CPRD (UK) & - & 596 & 970 & 1170 & 969 & 751 & 737 & 835 & 794 & 776 \\
\hline
\end{tabular}

$N L$ Netherlands, CPRD Clinical Practice Research Datalink, UK United Kingdom

${ }^{a}$ In Sweden, data from July 2005 were available, but only users from 2006 were included

number of topical tacrolimus users had increased to a level above that of 2004/2005, for both children and adults and in all countries. For topical pimecrolimus, the number of users remained relatively unchanged except in Sweden, where the decrease in the number of children using topical pimecrolimus continued through 2011.

In Denmark, the majority of children received topical tacrolimus with a strength of $0.1 \%$ (61\%) (Fig. 2) whereas a strength of $0.03 \%$ was predominantly dispensed to children $(56-69 \%)$ in all other countries. Adults were more often dispensed a topical tacrolimus strength of $0.1 \%$ in all countries (66-88\%). In the UK, a small number of patients (67 children and 260 adults) had dispensings for both topical tacrolimus strengths $(0.03$ and $0.1 \%)$ on the same day; these patients contributed to both groups in Fig. 2.

Overall, the number of users switching from initially prescribed topical pimecrolimus to topical tacrolimus was higher compared with users starting with topical tacrolimus and switching to topical pimecrolimus (Table 3). The number of children switching from topical tacrolimus to topical pimecrolimus during follow-up ranged from $1 \%$ in Sweden to $7 \%$ in Denmark. The number of children switching from topical pimecrolimus to topical tacrolimus ranged from $10 \%$ in the Netherlands and the UK to $13 \%$ in Sweden. Similar results were found for adults (Table 3).

\section{Discussion}

This is the first study evaluating the use of topical tacrolimus and topical pimecrolimus across four European countries in both children and adults. The results of this population-based multicentre database cohort study provide an overview of the use of topical tacrolimus and topical pimecrolimus in four European countries.

In this study, there was a difference seen in the type of TCI prescribed to children and adults across the four countries; in Denmark most children and adults were prescribed topical pimecrolimus, whereas in the other countries the preference was for topical tacrolimus. The use of topical tacrolimus and topical pimecrolimus increased in the first years after approval. This increase was steeper for topical pimecrolimus. There was a decrease seen in topical tacrolimus and topical pimecrolimus users in the Netherlands and Denmark from 2004 and in the UK from 2005. The number of users of topical tacrolimus increased again 

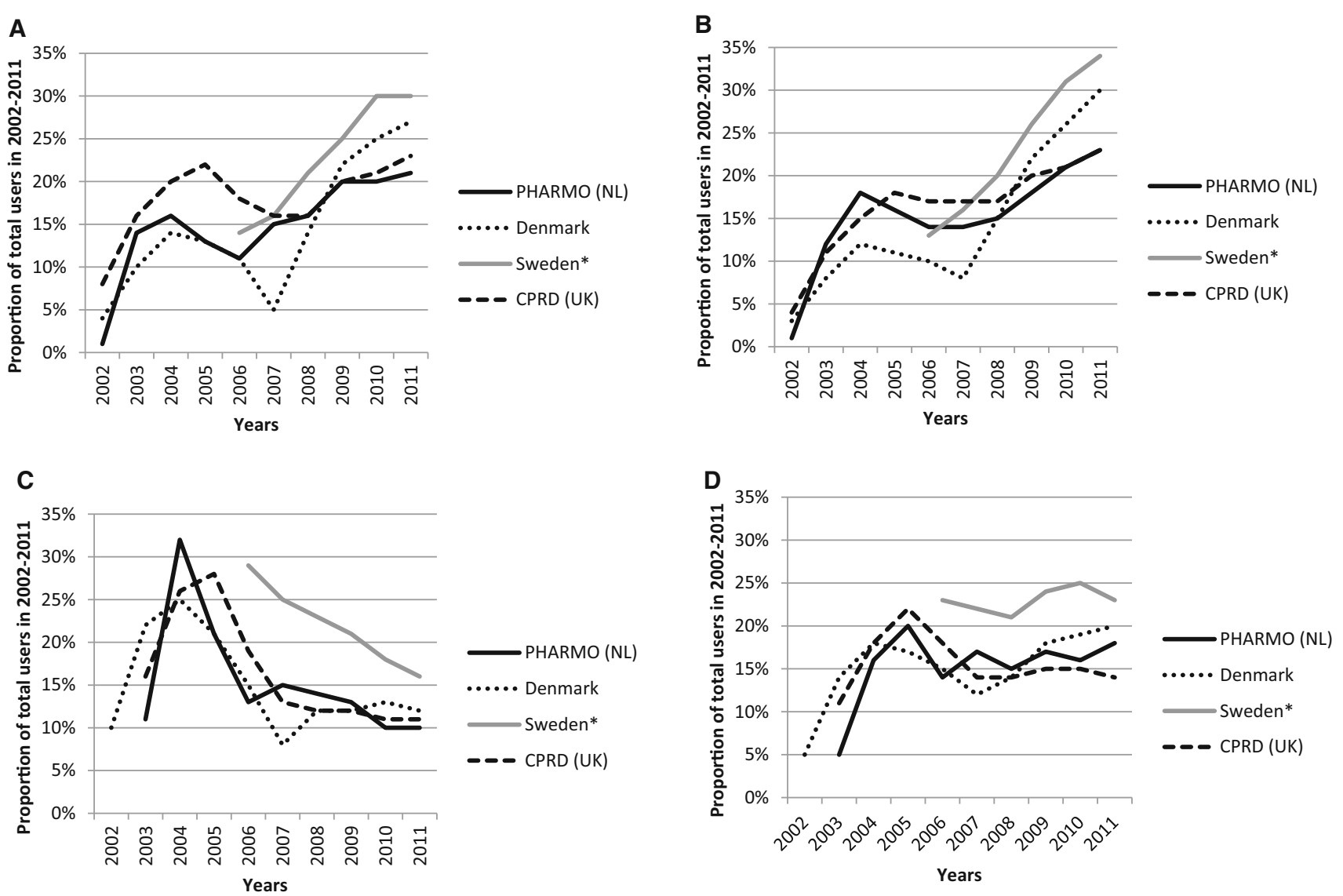

Fig. 1 Proportion of total users in each country over the years among a children using topical tacrolimus, $\mathbf{b}$ adults using topical tacrolimus, c children using topical pimecrolimus and $\mathbf{d}$ adults using topical

pimecrolimus, stratified by country. *In Sweden, data from July 2005 were available, but only users from 2006 were included

from 2007 onwards, while the number of users of topical pimecrolimus remained unchanged. For Sweden, data on an individual level were only available from 2006 and onwards. However, based on aggregate Swedish sales similar results were found compared to the other countries.

The pattern of use of topical tacrolimus and topical pimecrolimus may have been the result of the increased awareness of the concerns about a potential increased risk of skin cancer and lymphoma with the use of topical tacrolimus and topical pimecrolimus [14, 15], but there is no additional evidence to support this explanation. However, regulatory measures were undertaken, including a public health advisory in March 2005 and a label change in January 2006 [6, 7]. In the European Union as well as the USA the labelling of topical tacrolimus and topical pimecrolimus was updated by adding a warning about cautious use of topical tacrolimus and topical pimecrolimus in order to reduce the potential risk of skin cancer and lymphoma. In addition, a DHPC letter was sent by the marketing authorization holders of topical tacrolimus and topical pimecrolimus to healthcare professionals with important risk minimization measures, in accordance with the CHMP

[8]. Following the extension of the indication of topical tacrolimus to maintanance treatment of $\mathrm{AD}$ in the $\mathrm{EU}$ in 2009, a further reminder about minimization of cancer risk was sent to all healthcare providers [16]. However, this reminder seems to have less impact on the number of users of both topical tacrolimus and topical pimecrolimus.

The change in the pattern of use following these regulatory actions and responses from the the medical community was also seen based on worldwide sales data of topical tacrolimus and topical pimecrolimus published by Siegfried et al. [17]. Here, worldwide sales data of topical tacrolimus and topical pimecrolimus showed a decrease in sales within a year of the public health advisory and updated labelling. Comparable with the results in our study, the wordwide sales of topical pimecrolimus continued to decline, while the sales of topical tacrolimus slightly increased.

Topical tacrolimus and topical pimecrolimus are not indicated for children younger than 2 years of age. However, in our study, we know that off-label use of topical tacrolimus in children younger than 2 years of age did occur and ranged from $0.3 \%$ in the Netherlands to $3.7 \%$ in 


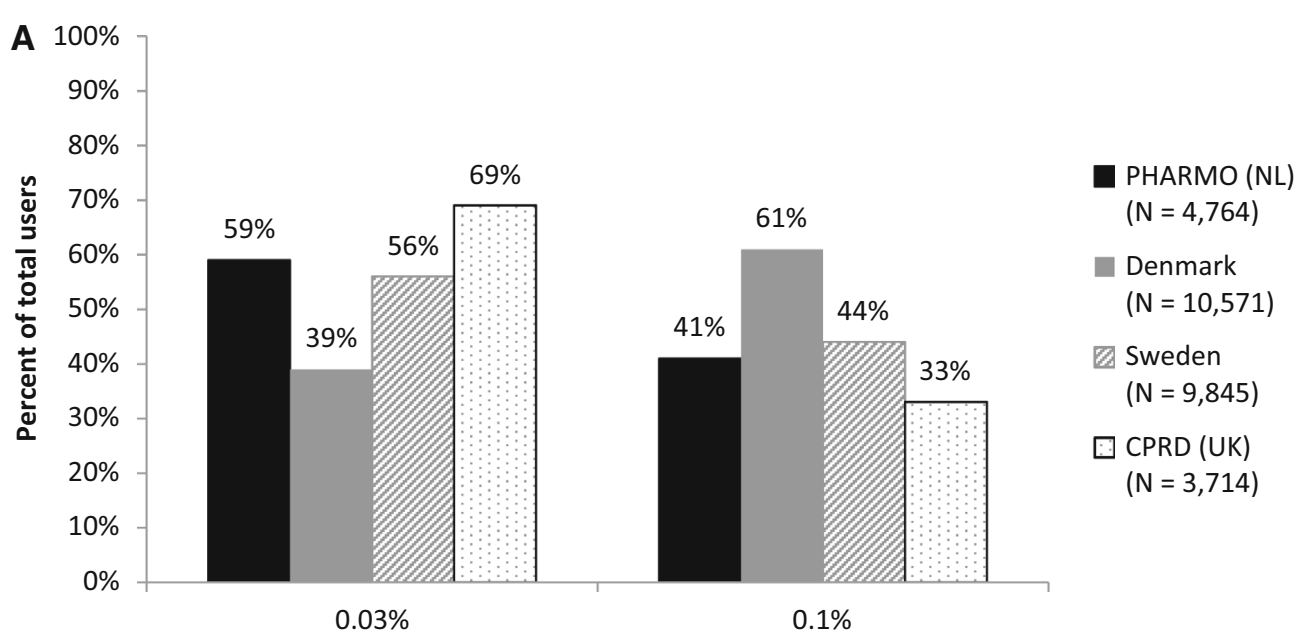

$\mathrm{NL}=$ Netherlands; $\mathrm{CPRD}=$ Clinical Practice Research Datalink; UK = United Kingdom; Note: In CPRD, 67 children and 260 adults had a dispensing for both a tacrolimus strength of $0.03 \%$ and $0.1 \%$ on the same day and contributed to both groups.

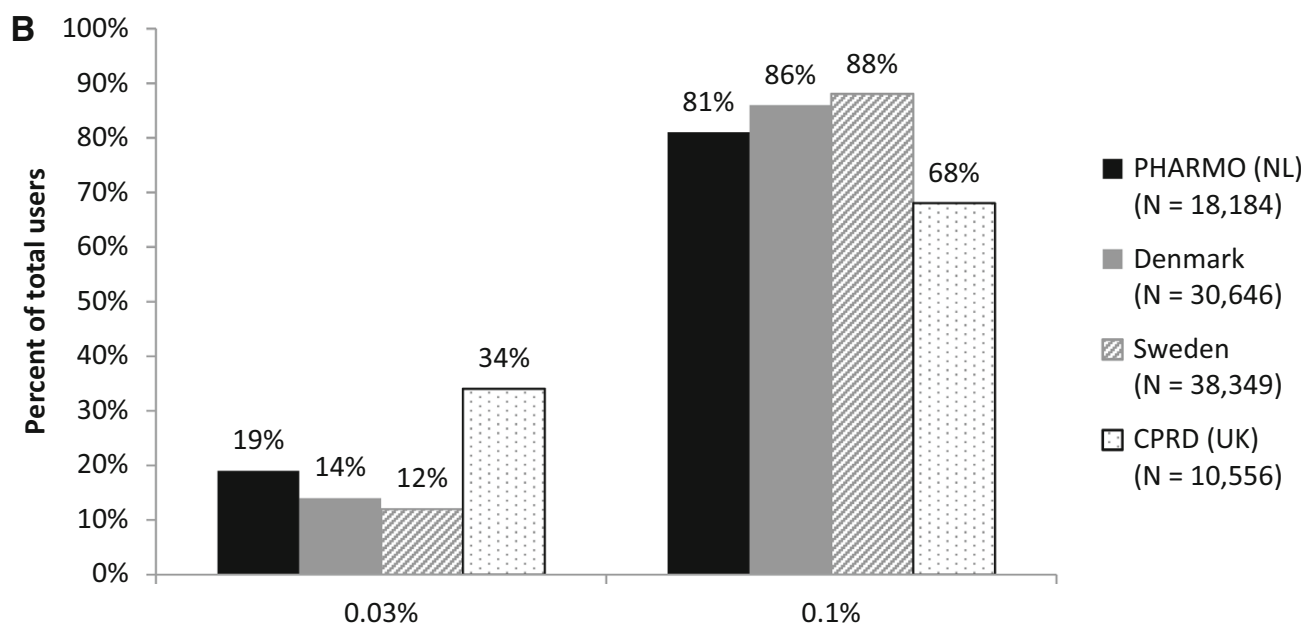

$\mathrm{NL}=$ Netherlands; $\mathrm{CPRD}=$ Clinical Practice Research Datalink; UK = United Kingdom

Fig. 2 Strength of first topical tacrolimus prescription among a children and $\mathbf{b}$ adults, stratified by country. Note In CPRD, 67 children and 260 adults had a dispensing for tacrolimus strengths of both 0.03

Denmark and for topical pimecrolimus from $1.4 \%$ in the Netherlands to $11 \%$ in Denmark (data not shown). A previous study also showed that off-label use of topical tacrolimus and topical pimecrolimus in children younger than 2 years of age decreased substantially in association with regulatory actions [18].

In this large population-based study in European databases, the data extraction and analysis for each health database were based on a common protocol that permitted combining the results across databases. However, some differences between the databases exist. In the UK, data on topical tacrolimus and topical pimecrolimus were obtained and $0.1 \%$ on the same day and contributed to both groups. $N L$ Netherlands, CPRD Clinical Practice Research Datalink, UK United Kingdom

from GP prescriptions, which do not contain information on whether the prescription was actually filled or not. For Denmark and Sweden, information on topical tacrolimus and topical pimecrolimus dispensings was obtained from national registers covering the entire Danish and Swedish population. In Sweden, full data on the number of users was available from 2006 onwards and the pattern of use on an invididual level could only be determined after that period. Data from the Netherlands and the UK were available for a subset of the population, but have been shown to be representative of the general population of these countries [13, 19-21]. 
Table 3 Switching patterns from first prescription of topical tacrolimus and topical pimecrolimus during follow-up, stratified by country

\begin{tabular}{|c|c|c|c|c|c|c|c|c|}
\hline & \multicolumn{4}{|c|}{ Topical tacrolimus cohort } & \multicolumn{4}{|c|}{ Topical pimecrolimus cohort } \\
\hline & $\begin{array}{l}\text { PHARMO } \\
(\mathrm{NL})\end{array}$ & Denmark & Sweden & $\begin{array}{l}\text { CPRD } \\
\text { (UK) }\end{array}$ & $\begin{array}{l}\text { PHARMO } \\
\text { (NL) }\end{array}$ & Denmark & Sweden & $\begin{array}{l}\text { CPRD } \\
\text { (UK) }\end{array}$ \\
\hline \multicolumn{9}{|l|}{ Children $(\leq 18$ years $)$} \\
\hline Number of users ${ }^{\mathrm{a}}$ & 4764 & 10,571 & 9845 & 3714 & 3188 & 23,324 & 1502 & 2869 \\
\hline $\begin{array}{l}\text { Number of switchers during follow- } \\
\text { up }^{\mathrm{b}}, n(\%)\end{array}$ & $307(6)$ & $693(7)$ & $124(1)$ & $241(6)$ & $311(10)$ & $\begin{array}{r}2649 \\
(11)\end{array}$ & $197(13)$ & $277(10)$ \\
\hline $\begin{array}{l}\text { Months between index date and first } \\
\text { switch, mean (SD) }\end{array}$ & $15.1(17.8)$ & $\begin{array}{l}23.6 \\
(25.9)\end{array}$ & $\begin{array}{l}15.3 \\
(13.9)\end{array}$ & $\begin{array}{l}20.2 \\
(20.7)\end{array}$ & $20.8(9.0)$ & $\begin{array}{l}26.5 \\
(27.8)\end{array}$ & $\begin{array}{l}22.2 \\
(16.9)\end{array}$ & $\begin{array}{l}19.6 \\
(20.8)\end{array}$ \\
\hline $\begin{array}{l}\text { Number of switchers during } \\
\text { childhood, } n(\%)\end{array}$ & $264(6)$ & $597(6)$ & $114(1)$ & $227(6)$ & $273(9)$ & $\begin{array}{r}2405 \\
(10)\end{array}$ & $174(12)$ & $266(9)$ \\
\hline $\begin{array}{l}\text { Months between index date and first } \\
\text { switch, mean (SD) }\end{array}$ & $18.8(21.1)$ & $\begin{array}{l}18.9 \\
(22.5)\end{array}$ & $\begin{array}{l}14.1 \\
\quad(13.1)\end{array}$ & $\begin{array}{l}18.6 \\
(19.2)\end{array}$ & $22.9(23.9)$ & $\begin{array}{l}23.9 \\
(26.5)\end{array}$ & $\begin{array}{l}20.7 \\
(15.9)\end{array}$ & $\begin{array}{l}18.5 \\
(19.6)\end{array}$ \\
\hline \multicolumn{9}{|l|}{ Adults ( $>18$ years) } \\
\hline Number of users ${ }^{\mathrm{a}}$ & 18,184 & 30,646 & 38,349 & 10,556 & 7028 & 37,566 & 4148 & 4837 \\
\hline $\begin{array}{l}\text { Number of switchers during follow- } \\
\text { up }^{\mathrm{b}}, n(\%)\end{array}$ & $909(5)$ & $1683(6)$ & $523(1)$ & 447 (4) & $680(10)$ & $\begin{array}{r}3743 \\
(10)\end{array}$ & $468(11)$ & $427(9)$ \\
\hline $\begin{array}{l}\text { Months between index date and first } \\
\text { switch, mean (SD) }\end{array}$ & $18.2(19.2)$ & $\begin{array}{l}23.2 \\
(25.6)\end{array}$ & $\begin{array}{l}16.1 \\
(15.1)\end{array}$ & $\begin{array}{l}19.5 \\
(21.1)\end{array}$ & $16.3(20.0)$ & $\begin{array}{l}26.7 \\
(27.5)\end{array}$ & $\begin{array}{l}21.5 \\
(19.0)\end{array}$ & $\begin{array}{l}16.7 \\
(19.3)\end{array}$ \\
\hline
\end{tabular}

$N L$ Netherlands, CPRD Clinical Practice Research Datalink, UK United Kingdom, $S D$ standard deviation

${ }^{a}$ Based on first prescription

${ }^{b}$ Follow-up continues into adulthood when data are available

\section{Conclusion}

In conclusion, the use of topical tacrolimus and topical pimecrolimus grew rapidly after regulatory approval. Safety warnings issued by regulatory agencies about a potential risk of cancer may have contributed to the temporary reduction in users of topical tacrolimus and persistent reduction in users of topical pimecrolimus in all countries, especially in children.

Acknowledgements The authors would like to thank the general practitioners for contributing information to the Clinical Practice Research Datalink (CPRD) in the UK and the healthcare providers for contributing information to the PHARMO Database Network. The research team chose the acronym JOELLE to honor of Dr. Joelle Erkens, pharmacoepidemiologist at Astellas and formerly at PHARMO Institute, who was lost to the research team in June 2011 upon her untimely death.

Disclosures Josephina G. Kuiper and Myrthe P.P. van Herk-Sukel are employees of the PHARMO Institute for Drug Outcomes Research. This independent research institute performs financially supported studies for government and related healthcare authorities and several pharmaceutical companies. Jordi Castellsague (retired), Lia Gutierrez, Brian Calingaert, Kenneth J. Rothman, James A. Kaye and Susana Perez-Gutthann are full-time employees of RTI Health Solutions, an independent nonprofit research organization that does work for government agencies and pharmaceutical companies. As employees of RTI Health Solutions, Susana Perez-Gutthann, Kenneth J. Rothman, and James A. Kaye, also participate in scientific advisory boards (for studies and medications) that are funded by pharmaceutical companies. Jesper Hallas and Anton Pottegård are employees of the Department of Public Health, University of Southern Denmark.
They have participated in studies funded by pharmaceutical companies (Alcon, Almirall, Astellas, Astra-Zeneca, Boehringer-Ingelheim, Servier and Leo Pharma), all with funds paid to the institution where they were employed (no personal fees) and with no relation to the work reported in this paper. Daniel Dedman and Arlene Gallagher are employees of the Clinical Practice Research Datalink (CPRD), which provides contract research services for government and related healthcare authorities, and pharmaceutical companies. Ingegärd Anveden Berglind and Anders Sundström were both full-time employees of the Centre for Pharmacoepidemiology at the Karolinska Institutet during the conduct of the study. They have both taken part in studies undertaken at the Centre, financed by pharmaceutical companies, but have never received compensation personally from any company. Carolina Pardo is an employee of Astellas Pharma Europe.

Funding The study was funded by Astellas Pharma. In June 2016, LEO Pharma became the marketing authorization holder of Protopic ${ }^{\circledR}$ and provided partial funding. The contract grants the research team independent publication rights. The sponsor had no role in the data collection or analysis and was not involved in the interpretation of results; however, in line with the ENCePP Guide on Methodological Standards in Pharmacoepidemiology [1], the sponsor had the opportunity to view the results and interpretations included in the manuscript and provide comments before submission of the manuscript for publication.

Data Availability All authors had full access to all the data in the study and all take responsibility for the integrity of the data and the accuracy of the data analysis. The datasets generated during and/or analysed during the current study are not publicly available for privacy reasons.

Open Access This article is distributed under the terms of the Creative Commons Attribution-NonCommercial 4.0 International 
License (http://creativecommons.org/licenses/by-nc/4.0/), which permits any noncommercial use, distribution, and reproduction in any medium, provided you give appropriate credit to the original author(s) and the source, provide a link to the Creative Commons license, and indicate if changes were made.

\section{References}

1. Guide on methodological standards in pharmacoepidemiology (revision 3). EMA/95098/2010. http://www.encepp.eu/standards_ and_guidances/methodologicalGuide.shtml. Accessed 20 November 2016. European Network of Centres for Pharmacoepidemiology and Pharmacovigilance (ENCePP).

2. Garg N, Silverberg JI. Epidemiology of childhood atopic dermatitis. Clin Dermatol. 2015;33:281-8.

3. Asher MI, Montefort S, Bjorksten B, Lai CK, Strachan DP, Weiland SK, Williams H, Group IPTS. Worldwide time trends in the prevalence of symptoms of asthma, allergic rhinoconjunctivitis, and eczema in childhood: ISAAC Phases One and Three repeat multicountry cross-sectional surveys. Lancet. 2006;368:733-43.

4. Cury Martins J, Martins C, Aoki V, Gois AF, Ishii HA, da Silva EM. Topical tacrolimus for atopic dermatitis. Cochrane Database Syst Rev. 2015;2015:009864.

5. Legendre L, Barnetche T, Mazereeuw-Hautier J, Meyer N, Murrell D, Paul C. Risk of lymphoma in patients with atopic dermatitis and the role of topical treatment: a systematic review and meta-analysis. J Am Acad Dermatol. 2015;72:992-1002.

6. FDA Approves Updated Labeling with Boxed Warning and Medication Guide for Two Eczema Drugs, Elidel and Protopic. http://www.fda.gov/NewsEvents/Newsroom/PressAnnouncements/ 2006/ucm108580.htm Accessed 20 Nov 2016.

7. FDA Issues Public Health Advisory Informing Health Care Providers of Safety Concerns Associated with the Use of Two Eczema Drugs, Elidel and Protopic. http://www.fda.gov/Drugs/ DrugSafety/PostmarketDrugSafetyInformationforPatientsandPro viders/ucm153960.htm Accessed 20 Nov 2016.

8. Scientific conclusions and grounds for amendment of the summary of product characteristics and package leaflet presented by the EMEA. http://www.ema.europa.eu/docs/en_GB/document_ library/EPAR_-_Scientific_Conclusion/human/000374/WC50004 6828.pdf. Accessed 20 Nov 2016.

9. Herings RM, Bakker A, Stricker BH, Nap G. Pharmaco-morbidity linkage: a feasibility study comparing morbidity in two pharmacy based exposure cohorts. J Epidemiol Community Health. 1992;46:136-40.
10. van Herk-Sukel MP, van de Poll-Franse LV, Lemmens VE, Vreugdenhil G, Pruijt JF, Coebergh JW, Herings RM. New opportunities for drug outcomes research in cancer patients: the linkage of the Eindhoven Cancer Registry and the PHARMO Record Linkage System. Eur J Cancer. 2010;46:395-404.

11. Pottegård A, Schmidt SAJ, Wallach-Kildemoes H, Sørensen HT, Hallas J, Schmidt M. Data Resource Profile: The Danish National Prescription Registry. Int J Epidemiol. 2017;46:798-798f.

12. Furu K, Wettermark B, Andersen M, Martikainen JE, Almarsdottir AB, Sorensen HT. The Nordic countries as a cohort for pharmacoepidemiological research. Basic Clin Pharmacol Toxicol. 2010;106:86-94.

13. Herrett E, Gallagher AM, Bhaskaran K, Forbes H, Mathur R, van Staa T, Smeeth L. Data resource profile: clinical practice research datalink (CPRD). Int J Epidemiol. 2015;44:827-36.

14. European Medicines Agency. Protopic: EPAR—scientific conclusion. http://www.ema.europa.eu/ema/index.jsp?curl=pages/ medicines/human/medicines/000374/human_med_001000. jsp\&mid=WC0b01ac058001d124. Accessed 20 Nov 2016.

15. European Medicines Agency. Summary information on referral opinion pursuant to Article 31 of Council Directive 2001/83/EC, as amended, for Elidel and associated names [EMEA/262776/2005]. Committee for Medicinal Products for Human Use (CHMP). http:// www.ema.europa.eu/docs/en_GB/document_library/Referrals_ document/Elidel_31/WC500012313.pdf. Accessed 20 Nov 2016.

16. Important safety reminder on PROTOPIC ointment and recommendations for monitoring with maintenance treatment. http:// webarchive.nationalarchives.gov.uk/20141205150130, http://www. mhra.gov.uk/home/groups/pl-p/documents/websiteresources/con07 5952.pdf. Accessed 20 Dec 2016

17. Siegfried EC, Jaworski JC, Hebert AA. Topical calcineurin inhibitors and lymphoma risk: evidence update with implications for daily practice. Am J Clin Dermatol. 2013;14:163-78.

18. Manthripragada AD, Pinheiro SP, MaCurdy TE, Saneinejad S, Worrall CM, Kelman JA, Graham DJ. Off-label topical calcineurin inhibitor use in children. Pediatrics. 2013;132:e1327-32.

19. Herings R, Pedersen L. Pharmacy-based medical record linkage systems. In: Strom B, Kimmel S, editors. Pharmacoepidemiology. 5th ed. Hennessy S: Wiley; 2012. p. 270-86.

20. van Herk-Sukel MP, Lemmens VE, Poll-Franse LV, Herings RM, Coebergh JW. Record linkage for pharmacoepidemiological studies in cancer patients. Pharmacoepidemiol Drug Saf. 2012;21:94-103.

21. de Jong RG, Gallagher AM, Herrett E, Masclee AA, JanssenHeijnen ML, de Vries F. Comparability of the age and sex distribution of the UK Clinical Practice Research Datalink and the total Dutch population. Pharmacoepidemiol Drug Saf 2016;25:1460-4. 